\title{
High-Performance Natural Dyes for Cellulosic Fibers Review - part 1
}

\author{
Nancy Sid, S. EL-Hawary \\ Dyeing, Printing and Auxiliaries Department, Textile Industries Research Division, \\ National Research Centre,Egypt.
}

\begin{abstract}
$\mathbf{E}$ NVIRONMENTAL issues and environmental protection laws are a global trend that imposes on us to use clean and environmentally friendly technologies, reduce toxic emissions, deal with environmentally and human harmful chemicals, and introduce modern technologies into production processes. It is well known that textile industries use many chemicals and chemical dyes contaminated with the environment, which necessitates the need to use non-harmful dyes as well as the tendency to use natural raw materials. These dyes were not harmful to natural pigments in the first place; meanwhile, they constituted a trend where natural fibers were used. Hence, cellulose became a major importance global trend for everything from natural origin, such as cotton, jute and linen. In addition, use of natural colorants on these fibers has become very much popular throughout the world by virtue of its eco-friendliness, and aesthetic approach.
\end{abstract}

\section{Introduction}

The rapid search steps in synthetic chemistry backed by the manufacture of textiles have not only produced artificial alternatives to the famous natural dyes, but then it led to the number of artificial dyes that are innumerable colors and colors that led to gradual forgetting of natural dyes. Once again, the issues of the manufacture and use of artificial dyes recharged customer interest in natural dyes through the last decades of the 20 th century.

Consumers interested in the environment prefer colored textiles in natural colors, and today there is a position market for such textiles. The use of natural dyes launched to weakening after the discovery of artificial dyes in the second half of the nineteenth century. Coordinated research efforts in the field of artificial dyes and the fast fabrication of textile manufacture have to lead in approximately complete unused of natural dyes by artificial pigments because of they easily available in the ready-to-application form, the application process is simple, consistent shading and well stability characteristics. Eco-friendly alertness has paid attention to natural dyes, especially among people with a green awareness.
Natural dyes are ecologically aware because they are renewable and recyclable. They are pleasant to the skin and may also provide health assistance for wearers [1].

On the other hand, the uses of natural plants are equally important in industries. Recent environmental interest in the use of plant fibers has led to intensive research into the characteristic properties of natural fibers to replace energy-intensive synthetic fibers, especially in the manufacture of the compound. With large spending cuts in defense and aerospace programs, some multinationals are reorienting their high-price, great-act vehicles into more environmentally rigid, minimum power-efficient and less expensive plant fiber. It is also known that the fiber plant is carbon neutral and therefore ecologically kindly. The low specific thickness of cellulose-based fibers chiefs to mass investments in complex industrial development with direct advantages over transport [2].

\section{Cellulosic fibers:}

Cellulose comes from natural plant fibers such as cotton, flax, hemp, jute, sisal, banana, coconut, bamboo, and the like, offering many benefits for synthetic items such as abundance, 
low cost, renewable, eco-friendly, low density and specific properties are high. Some of these natural plants such as cotton and linen, among others, provide excellent comfort for clothing and, therefore, are very popular and widely used in the garment sector. The properties of cellulose are influenced by many factors such as diversity, climate, harvest, maturity, elevation, scaling and disintegration (mechanical processing and steam emission), left classification, textile and technical processes (spinning and sculpture) [2].

From the simpler chemical point of view, cellulose is a natural polymer, with long chain anhydro-D-glucopyranose units (AGU) and each cellulose molecule having three hydroxyl groups per AGU, with the exception of the terminal ends. $[3,4,5]$ as shown in fig. 1 .

\section{Natural dyes:}

The word 'natural dye' covers all the dyes derived from the natural sources like plants (e.g., indigo and saffron); insects (e.g., cochineal beetles and lac scale insects); animals (e.g., some species of mollusks or shellfish) and minerals (e.g., ferrous sulfate, ochre, and clay) without any chemical treatment. Indigoid dyes are perhaps the oldest natural dyes used by man. Indigo is the only important natural blue dye. Leaves of the plant indigofera tinctoria are the best source of this dye. This very important dye popularly known as the "king of natural dyes" has been used from ancient times till now for producing blue color and is today most popular for denim fabrics. The coloring matter is present in indigo plant leaves as a light yellow substance called indicant (1H-indol-3yl b-D-glucoside). The leaf production from one acre of cultivated indigo plants is approximately $5,000 \mathrm{~kg}$ which can yield about $50 \mathrm{~kg}$ of pure natural indigo powder after processing. It is produced by fermenting the fresh plant leaves, and cakes thus prepared are used for dyeing purposes. Apart from indigofera species, there are several plants that can be used to produce indigo dye. Woad is a natural indigoproducing plant in Europe. Apart from this, dyers knotweed (Polygonum tinctorium) and Pala Indigo (Wrightia tinctoria) are some of the plants used to produce indigo traditionally. The use of natural indigo started declining after the manufacture of synthetic indigo by BASF in 1987 [7].

As shown in Fig. 2, natural dyes are widely used in many industries like producing confectionery, other coloration of food products, textiles, cosmetics, medicines, leather processing, paper, paint, ink, etc. [9]. Natural dyes can be used for dyeing almost all kinds of natural fibers. Latest investigation shows that it can be used to dye some synthetic fibers. There are many tasks and associated limitations with using natural dyes. Given this fact, the use of natural dyes in the present textile treating is a great challenge $[6,7]$. However, over the past few periods, ecological worries relate to the use of most synthetic dyes, research and development researchers around the world to explore new environmentally friendly alternatives to minimize negative environmental impacts, and various aspects of bio-coloring applications [8].

Natural dyes have been classified in a number of ways (Fig. 3). The main origin of classification of natural dyes is their assembly sources, application devices on textiles and their chemical structure $[10,11]$.

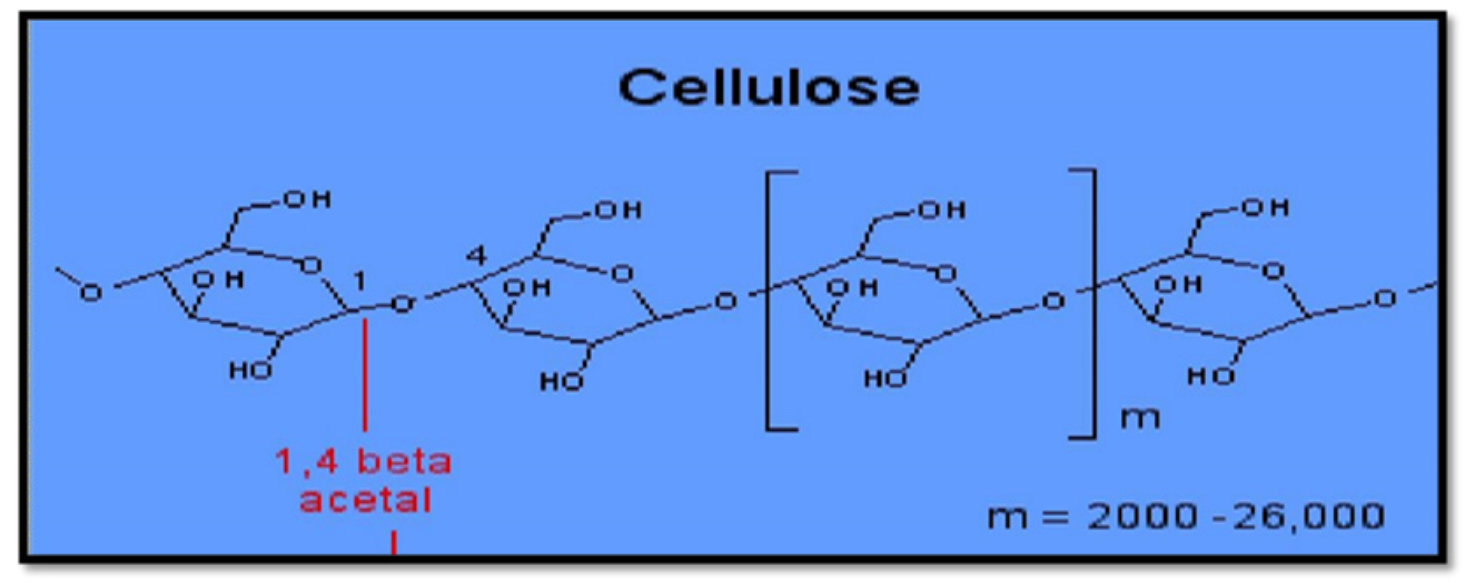

Fig. 1. Cellulose is a long chain.

\section{J. Text.Color. Polym. Sci.,16, No. 1 (2019)}




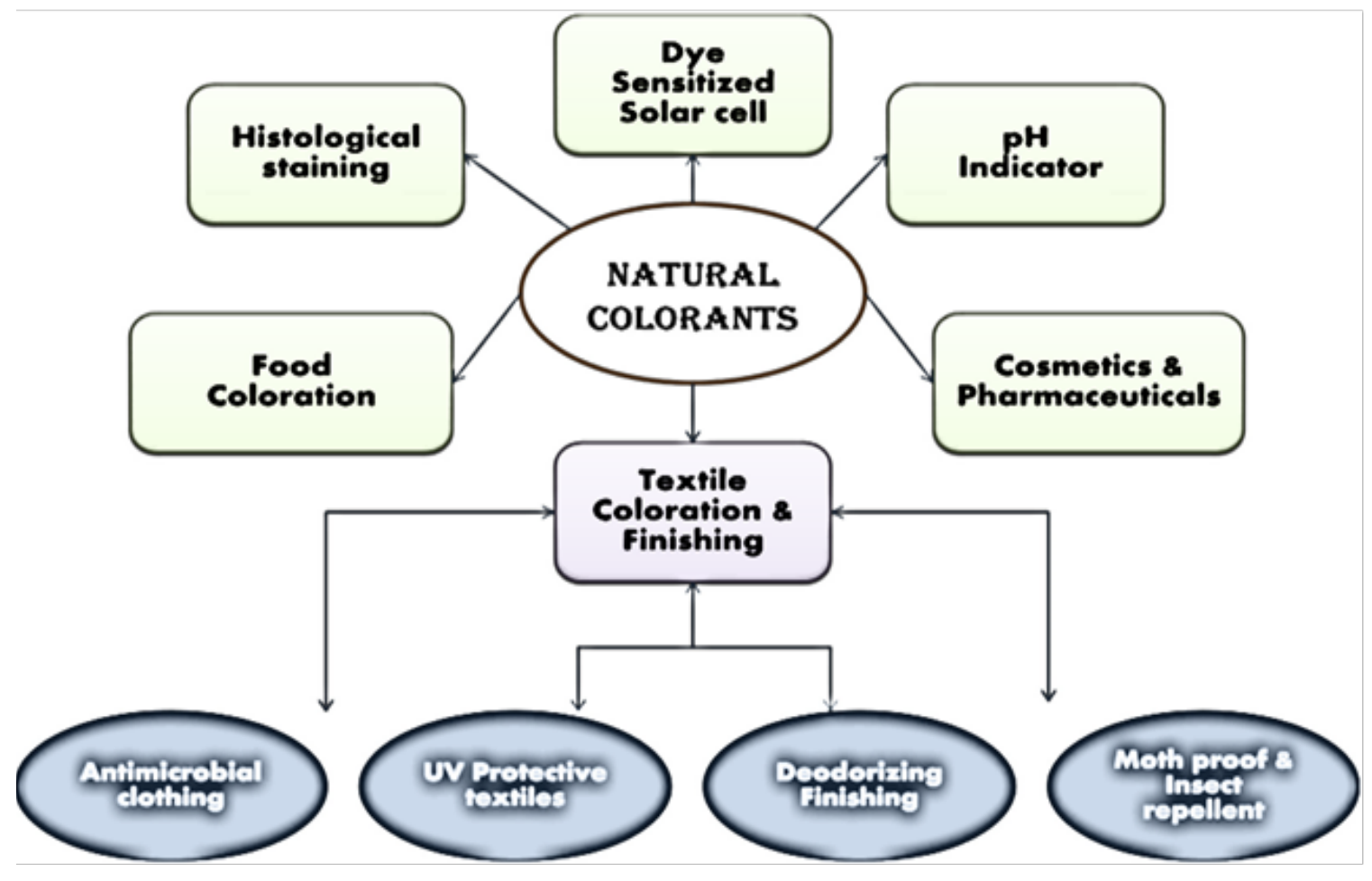

Fig. 2. Application of natural colorants.

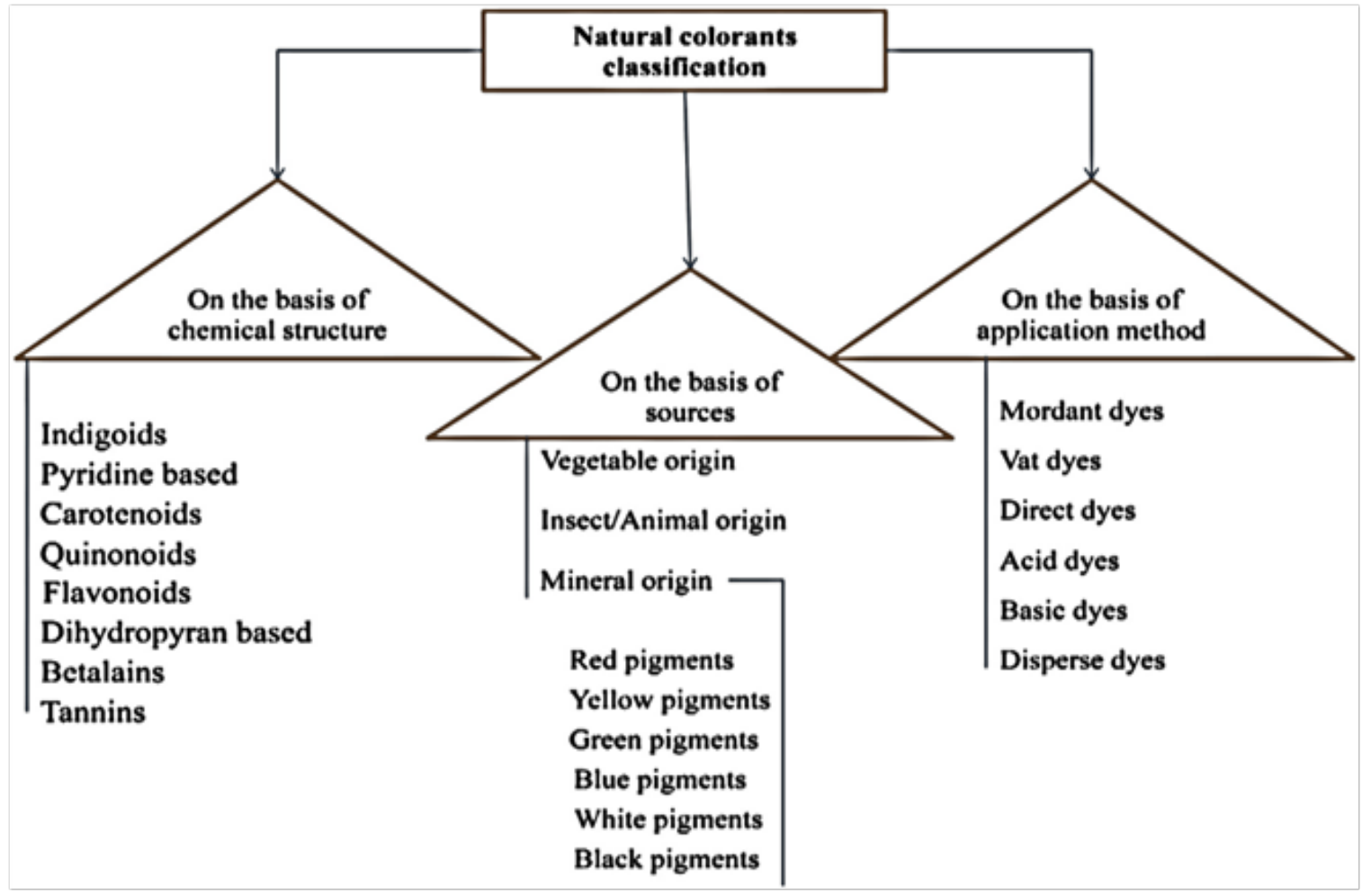

Fig. 3. Classification chart for natural colorants. 
Advantages of natural dyes:

In current centuries, there has been a boom in the field of natural dyes. Mostly due to the fact that although artificial colors are fast, durable and relatively easy to apply, the natural dyes have certain advantages can be summarized as follows: a) Fairly non-polluting and have lower toxicity.

b) They have a soft, glossy and comfortable shade for the human eye.

c) Can be used as natural dyes to obtain carbon credit by reducing the consumption of synthetic dyes based on fossil fuels (petroleum) $[12,13]$.

d) They produce a wide range of colors. A slight difference in dyeing technique or the use of different mordant with the same dye can create entirely new colors can not be achieved using artificial dyes.

e) Natural dyes are usually mothproof and can replace synthetic dyes in children's clothing and food safety.

f) Some natural dyes are enhanced with age, while synthetic dyes fade over time.

g) Some of its components are anti-allergic, and therefore proven to be safe for contact and are mostly non-hazardous to human health. [14].

Disadvantages of natural dyes:

Natural dyes display several disadvantages, which are given under:

a) The extraction, preparation of textile materials and mordanting, as well as natural dyeing, needs skilled craftsmanship which makes the utilization of natural dyes expensive.

b) It is hard to characterize a formula for the use of natural dyes because the process of natural dyeing and color evolution not only depend on color component but also on materials [12].

c) The dyed textile may transformation color when visible to the sunlight, perspire and air.

d) Scientific support for much of the science of natural dyeing should be sought further.

e) On the whole, all-natural dyes require with a little exclusions need the use of mordant to fix dye on to the textile substrate. Thus, by using dyeing, a large part of the sediment can not be salvaged in the remaining dye bath and, therefore, may pose a serious problem for the disposal of liquid waste. [14,15].

J. Text.Color. Polym. Sci.,16, No. 1 (2019) f) The unavailability of natural dyes in pure or uniform form, such as powder, paste or solution makes the ease of direct application in the known shadow ratio difficult or impossible in some cases.

High-performance extraction process of color component natural dyes on cellulosic fibers:

Extraction of dyes from the natural sources could be considered as one of the greatest significant stages in the textile processing to achieve the characteristics of dyeing and/or antimicrobial actions. Of equal importance is the establishment of a standard extraction process and adjusting the extraction variables for a specific natural resource since extraction standardization and optimation of the extraction variables are economically important by virtue of their impact on the price of the end products. The chromatic component should also be extracted for concern so that it can be applied appropriately to textiles.

The various techniques for extracting natural coloring matters are:

- Conventional extracting methods:

1- Aqueous extraction

2- Alcoholic/ organic Solvent extraction

3- Alkali or acid extraction

4- Fermentation technique

- High-performance extraction techniques

1- Enzymatic treatment

2- Ultrasonic extraction

3- Microwave extraction

4- Enzyme-ultrasonic extraction

5- Ultrasonic and other traditional extraction method

- As there is a lot of research work in the field of ultrasonic and Enzyme-ultrasonic assisted extraction techniques, so I will discuss these research work in details

\section{Conventional extraction technique:}

Aqueous extraction:

In order to improve the extraction method of the water component in a water medium, the dried and soft source material is melted form the natural dye to powder in which the colored element is extracted into the water by using a standard process. The water extraction of the dye liquor 
is performed under different conditions, such as extraction time, extraction temperature, $\mathrm{pH}$ in the bath used as extraction fluid, and concentration of the source material (the powder representing the source natural dye material). Ratio of materials to liquor [16]. Several professors have informed the optimal process for extracting natural dyes from the source, Sinha and Datta, extract the Butterfly pea (Clitoria ternatea) at different long intervals from $10 \mathrm{sec}$ up to $2 \mathrm{~min}$ by aqueous extraction method at $30 \mathrm{~min}$ to $3 \mathrm{~h}$. Color strength and yield of dye extracts were studied using UV spectrometer [17]. On the other hand, pomegranate (known as tanante of pelletierine) was selected as a coloring material (University of Agriculture, Faisalabad, Pakistan) in boiling for $1 \mathrm{~h}$. in order to dye cotton fabric. The results obtained indicate that color strength is highly dependent on the extraction time and that the samples have good stability properties with deep shadows [18].

\section{Alcoholic/organic solvent extraction:}

This is done using applicable extraction equipment, for example Soxhlet device and solvents such as alcohol, hexane or gasoline solvents. The method of extraction of water/ alcohol is technically feasible to extract soluble substances in water and insoluble substances in water from the plant sources. Consequently, the extraction output is higher than the water method because more chemicals and coloring materials can be extracted.

Khattak et al. isolated color from cutch root; a solvent extraction procedure was performed with soxhlet apparatus, using ethanol as an organic solvent. The rotary evaporator was used to evaporate the solvent [19].

Alkali or acid extraction:

Many of the dyes are in the form of glycosides, which can be extracted under acidic or alkaline conditions. The adding of acid or alkali smooths the hydrolysis of glycosides resulting in enhanced extraction and higher efficiency of coloring materials $[7,18]$.

\section{Fermentation technique:}

The extraction method uses the enzymes produced by the microorganisms in the atmosphere or those in natural sources to assist in the extraction process. Indigo extract is the most common example of this type of extraction.

Shuvo et al. discussed the methodology required for the formulation of a successful chemical recipe for cellulosic cotton substrate dyeing using natural indigo vat dyes in aggregation with the available commercial chemical products as well as the confirmation of the optimal fastness property of the dyed substrate surface. Fermentation groups in the nano-dim containing the indican glucoside present in the leaf decomposes to glucose and indoxyl by anymulsin enzyme. The process of fermentation is carried out in ten to fifteen hours. Then the yellow solution which contains indoxyl is air-oxidized and turned to bluish shade (insoluble indigotin). Then this solution is gathered, washed, and after getting rid of excess water, is squeezing into cakes. Indigo can be extracted from other sources, for example, woad. Similarly, this procedure may be utilized for extraction of annatto. The technique of fermentation is like the aqueous extraction technique but doesn't need high temperature in the procedure. [20].

The disadvantage of these traditional techniques refers to coloring materials that can be destroyed under alkaline conditions. Some natural dyes are known to be sensitive to $\mathrm{pH}$. In addition, long extraction time, large water requirement and the use of high temperature, low dye production because the water soluble dye components are only extracted while many other dyes have low solubility in water. Therefore, scientists continued to search for other methods and techniques for natural extraction processes that provide time, water, chemicals and energy meanwhile at the same time is kept safe for the environment and human health.

\section{High-performance extraction technique:}

Enzyme extraction:

Over the past three decades, new treatment technologies have been adopted that rely on the enzymes in different areas of the textile industry. Biotechnology based techniques using enzymes such as Cellulase, amylase and pectinase are useful for the following reasons: moderate treatment conditions, harsh chemicals substitution, work specificity, safe and easy to control, environmentally friendly, biodegradable, and economical. There are ongoing efforts to replace harsh chemicals with enzymes in processing textiles [21].

A single-bath dyeing for linen fabric with natural dyes has been devised by Curcuma longa, Logwood and Pomegranate. In this process, ElZawahry et al. use one or more complex enzymes with tannic acid and a natural dye [22]. Based on the enzyme complexes of the advanced J. Text.Color. Polym. Sci.,16, No. 1 (2019) 
natural dyes, the effectiveness of four enzymes was determined. The selected enzymes, neutral cellulase, protease, $\beta$-amylase and lipase, as well as three mixtures of these enzymes viz. $\beta$-amylase + lipase, neutral cellulase + lipase and neutral cellulase $+\beta$-amylase. Wide variation in shade, degree of color depth can be achieved by applying enzymes and mixtures of enzymes in dyeing methods. Color data show improved dyeing using these enzyme complexes. Both the four enzymes and their mixtures were found to be highly effective. When used together with tannic acid in refining the stability washing fastness of the three natural dyes. The use of enzyme/tannic acid/ natural dye complexes interchanges metal mordant making natural dyeing procedure environmental.

Zhao Y. et al. extracted anthocyanin in indigo slag with cellulase and pectase by enzyme hydrolysis extraction method [23], it was found that the extract yield by adopting composite double enzyme hydrolysis was 3.05 and 1.53 times higher than cellulase and pectase used by itself respectively.

Cai J. et al. researched the application of enzyme in lycopene extraction process [24], the result was that extract time can be reduced by adding pectase and cellulose simultaneously. Qiu B. et al. compared water extract and pectase by adding in the extract process of gardenia yellow [25], the conclusion was, the extract yield of gardenia yellow with the presence of pectase was higher than that of traditional extraction.

Enzymatic actions employed in extraction, result in decreased chemical consumption. There are many advantages of enzymatic extraction. Few are given below:

a) Their specificity and selectivity are not only for particular reactions but also in their discrimination between similar parts of molecule.

b) Interaction can be stimulated to exclude side reactions and eliminate undesirable byproducts.

c) The enzyme works under generally mild processing conditions of temperature, pressure and $\mathrm{pH}$, hence decreased the energy requirements.

d) Increase in productivity with reduced manufacturing costs due to wages and overheads.

J. Text.Color. Polym. Sci.,16, No. 1 (2019)

\section{Ultrasonic extraction technique:}

Ultrasound consists of pressure waves at frequencies of $20 \mathrm{kHz}$ or more. Such as optical and acoustic waves, can focus ultrasound waves and break through the means. Other ultrasound is classified by frequency range such as ultrasound $(20-100 \mathrm{kHz})$ and diagnostic ultrasound (1-10 $\mathrm{MHz}$ ). While ultrasonic fluid is irradiated, small bubbles look, grow and oscillate very quickly and even aggressively breakdown if the sound pressure is high enough. If these breakdowns happen, a solid surface will produce sodium and lightning waves. Also, in the fluid phase containing the particles, increasing the micromaxing will increase heat and mass exchange and even propagate the species within the company pores $[26,27]$. When ultrasound is absorbed in the fluid system, the cavity phenomenon occurs. The cavity can release trapped gases from liquid or porous materials like textiles, dyebath etc. The effect of ultrasound is explained three directions:

(I) Dispersion: Crushing of high molecular weight solids and aggregates in uniform dispersion.

(11) Discharge: Evaporation (dissolved or trapped gases or air particles and gaps at the junction points to liquid and removed cavity.

(IIl) Spread: Accelerating prevalence rate inside the material by penetrating the insulating layer covering the material and speed up the reaction.

It has been observed, in particular, that some interactions when subjected to ultrasonic energy become faster with lower temperature and this is the most beneficial effect because it reduces processing time and energy consumption and improves product quality in textile coloring. [28].

Other sample, Kamel et al. use the highest ultrasonic cleaner bath for inhalation of coloring from different plant. The results indicate that the extraction by ultrasound at $300 \mathrm{~W}$ was more active at lower temperatures and times than conventional extraction [29].

Approximately, Abdul Rahman et al. used $7 \mathrm{~g}$ bark of Xylocarpus moluccensis and $1 \mathrm{~g}$ of the heartwood planet were used and placed in the bottle. $80 \mathrm{~mL}$ of $0.1 \mathrm{M}$ sodium hydroxide was added. Then put the bottle in ultrasonic cleaning the extraction process. The optimum coefficient is ultrasonic volume (low, medium and high), time extraction (20, 40, 60, 80 and 100 minutes) and reading the temperature after extraction. 


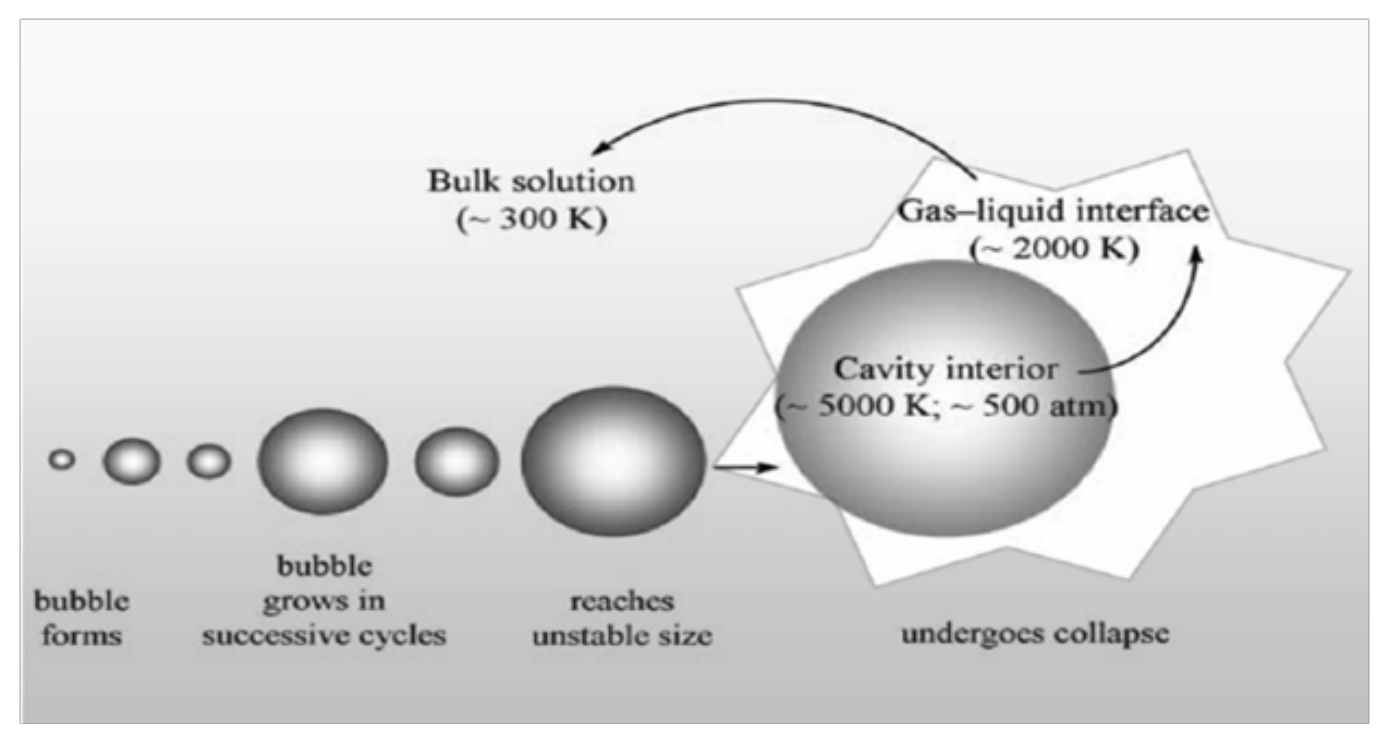

Fig. 4. The formation and collapse of a cavitation bubble, and three reaction zones (i.e., cavity interior, gas-liquid interface, and bulk solution) in the cavitation process.

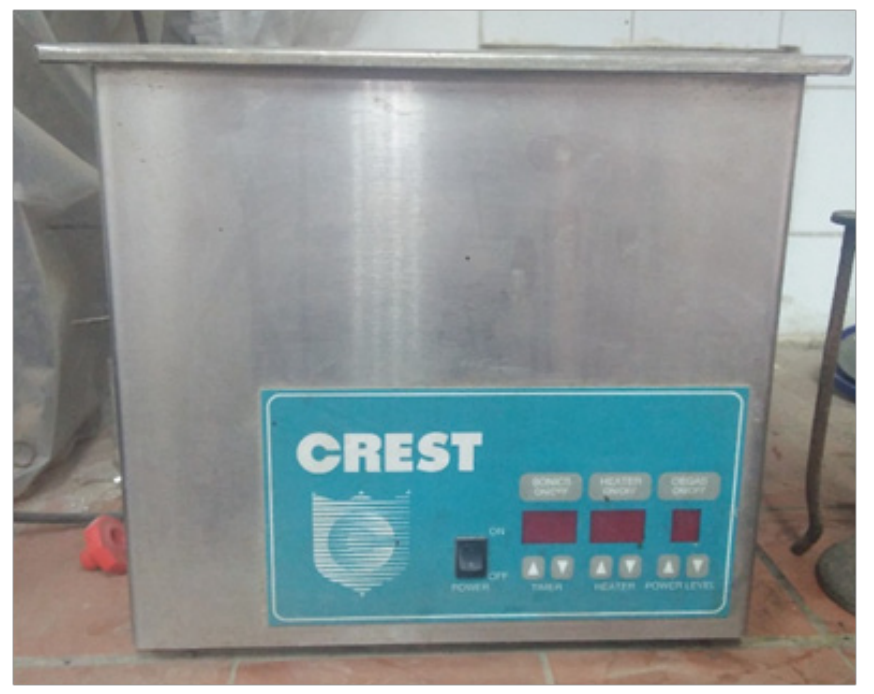

Fig. 5. Ultrasonic water bath.

All extracts were filtered using a vacuum pump and value * indicating that the reddish effect of raw pigmentation was significantly higher using ultrasonic extraction than the conventional boiling method [30].

On the other hand, Mishra et al. Performance of ultrasound-assisted extraction technique for the extraction of colorant from Dahlia variabilis has been compared with conventional solvent extraction method and the yield of spray dried colorant is found to be $10-11 \%(\% \mathrm{wt})$ of dry petals.
However, the yield of solvent extraction under similar conditions under reflux for 90 min was found to be significantly low $7-8 \%$ ( $\% \mathrm{wt}$ ) for dry petals. Ultrasound-assisted extraction technique is known to accelerate swelling and cause an enlargement in the pores of the plant cell walls; it might have facilitated mass transfer of solute constituents from the plant materials to solvent. The disruption of plant cells by micro-jet after the collapse of cavitation bubble results in increasing rate of solvent penetration into plant tissue. These factors must have collectively responsible for the J. Text.Color. Polym. Sci.,16, No. 1 (2019) 
higher yield and less reaction time in Ultrasound as compared to solvent extraction. A faster extraction rate of up to 15 minutes indicates a high concentration of contamination coloring between solvent and petals and easy extraction from the surface of petals in the early period [31].

Results indicate by Febriana et al. that there is about $9.2748 \%$ improvement in the yield of extraction of Swietenia mahagoni due to increasing extraction temperature from $30^{\circ} \mathrm{C}$ to $50^{\circ} \mathrm{C}$. The effect of increasing temperature causes increasing the number of cavitation bubbles and the surface contact area meanwhile the extraction time is faster than conventional extraction [32].

Although, Zhao C. et al, extracted lycopene from fresh tomato by auxiliary function of ultrasonic extraction [33], the content of lycopene in the extracted solution was $55.72 \mathrm{mg} / 100 \mathrm{~g}$ under the optimum process by ultrasonic method.

Wang B. et al. extracted capsicum red by ultrasonic method [34], it was found that the extract yield of capsicum red reached $10.68 \%$, with less pollution, short time, high yield and purity. Similarly, Jiang et al. studied the process of extracted orange peel dyestuff by ultrasonic technology [35].

\section{Microwave extraction technique:}

Microwaves (MW) are electromagnetic waves whose frequency ranges from $1000 \mathrm{MHz}$. to 10,00,000 MHz. [36]. Microwaves, which have broad frequency spectrum, are electromagnetic waves that are used in radio, TV and radar technology $[37,38]$.

In other words, wavelengths of microwaves are short in the frequency range above, usually from few cms to few $\mathrm{mm}$. The high-frequency edge of the microwave boundary on the infrared region and the visible light from the spectrum [37]. Microwave is a form of electromagnetic energy, where applied energy is converted into heat through the interplay of media (the component of the electric field of the wave with particles charged in the material). Micronutrient radiation provides more homogeneous heating in the reaction mixture than normal heating methods. The reaction mixture sample is heated more efficiently inside it. This reduces the effect of the wall due to internal heating. So hyperactivity occurs. In normal heating methods, the outer wall is heated at first. The outer surface of the liquid is heated and the temperature rises to the center. In this type of heating method, a constant J. Text.Color. Polym. Sci.,16, No. 1 (2019) temperature difference occurs between the outer and central surfaces. In the case of MW heating, each point of the solvent is heated regularly. Thus making it possible to reach higher temperatures faster than normal heating methods (Fig. 13) [38].

Compared with traditional heating performances, microwave heating has other benefits: internal heating, higher heating degrees, selective heating, greater heating control, lack of direct contact between heating source and heated materials, and reduced equipment size and waste $[38,39]$. There are actually microwave-assisted extraction processes where the extraction power is increased by the use of microwaves thus reducing the amount of solvents required, time, and extraction temperature [7]. In microwave extraction, the natural sources are treated with a minimal solvents in the presence of microwave energy sources. The microwave increases the processes rate so the extraction can be completed in a shorter time with better productivity.

Sinha et al. reported extraction with the help of a microwave-assisted blue pigment from the butterfly pea [40]. Microwave extraction can be considered as green processes due to low extraction temperature, solvent use, and time, resulting in lower energy consumption.

Mahfud et al. has been used to extract Coleus atropurpureus leaf in a domestic microwave oven. The extraction process is carried out in a three-layer vial extractor with a condenser placed at the top of the oven. The raw materials were grinded, sorted to a certain size (35-60 mesh). Powder and solvent were fed into the extractor. Water flow on the cooling system (condenser). After the extraction process completed in the oven, the extract is filtered with the filter paper (whatman no.1, $90 \mathrm{~mm}$ diameter) using a vacuum filter. Comparison of microwave extraction and traditional ethanol extraction method, the boiling point of ethanol is $78^{\circ} \mathrm{C}$ and does not lead to degradation of the dye (natural dye) so that the ratio of the material to the smaller solvent in the extraction system can cause the solvent to be more in contact with the material. This leads to more dye that can be extracted. Achieving the boiling point more quickly causes the solvents to evaporate faster, leading to a reduction in the solvent size to the materials [41].

Hassan et al. have repeated a study concerned with exploring feasibility of using the mesocarp and exocarp of Cocus Nucifera as a natural 
colorant. Microwave-assisted extraction of materials often regarded as a waste material were employed [42]. The results exhibted that heating time and microwave power affected slightly. The $\mathrm{pH}$ of all samples due to $\mathrm{pH}$ being inconsistent throughout the experiment. The use of microwave assisted extraction has significantly improved the extraction of natural coloring compared to the conventional method of boiling. In fact, the application of the microwave radiation method has been proven to be a rapid and improved technique for extracting natural coloring and reducing the time of mass extraction.
On the other hand, Hemanthraj et al. have made use of the response surface methodology to optimize the Solvent, Microwave-assisted extraction of natural dye from Pterocarpus santalinus wood. Microwave-assisted extraction method dictates the quality, economics and environmental impact of any plant processing. It shows a highly promising future with drastic reduction in extraction time resulting in higher sample throughout without significant losses in analyses recovery [43].

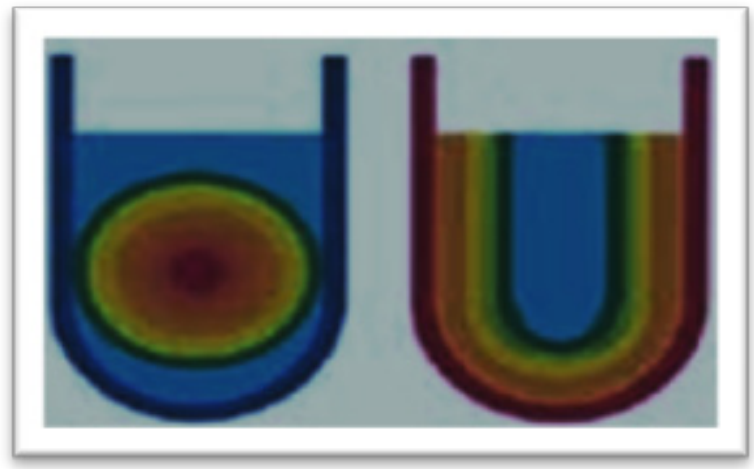

Fig.6. Microwave heating and conventional heat dissipation.

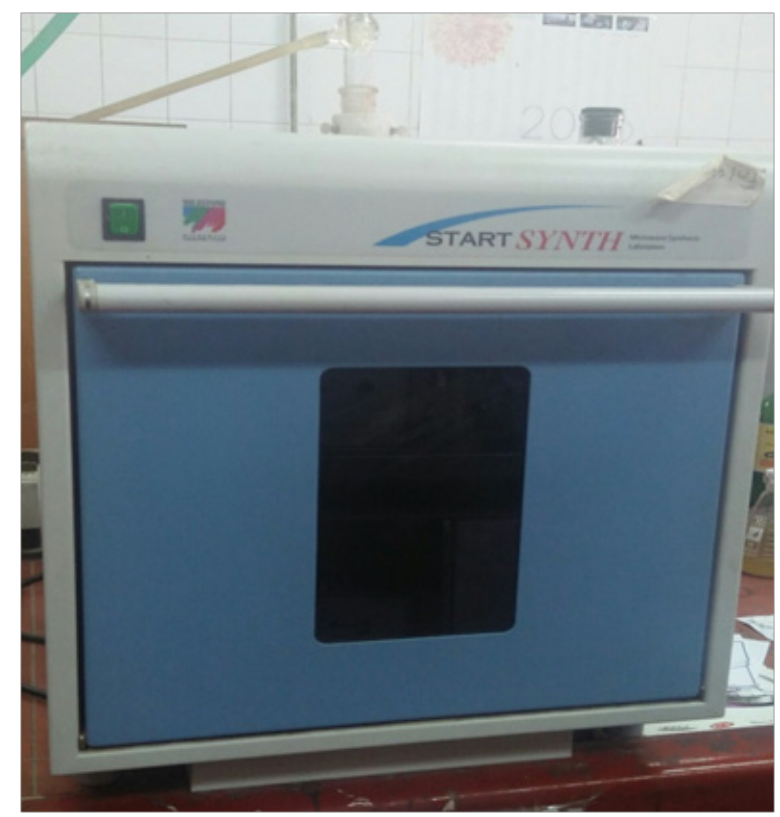

Fig. 7. Microwave Extraction.

J. Text.Color. Polym. Sci.,16, No. 1 (2019) 
Ahmad et al. The domestic microwave oven was developed which was used for rapid extraction of dyes from the Pycnoporussanguineus species. Microwave oven power was set at 300, 450 and 600 watts and exposure time with microwave radiation was 5 minutes. For comparison, extraction was also performed using conventional extraction method. It can be said that the fabric absorbs more pigments with the microwave method. It can be used as an alternative to extracting fungus pigments because the method can extract the dye particles more in a short time (10 minutes). Therefore, microwaves cause rupture of glandular walls of materials rapidly, leading to higher extraction efficiency in a shorter time. In addition, microwave energy has also played an important role in the extraction of Pycnoporussanguine dyes [44].

\section{Enzyme-Ultrasonic extraction technique:}

The traditional extractions, such as water extract, heating drying method causes a certain environmental pollution and numerous energy consumption due to the organic solvent used in separation and purification for the extraction process, so the clean extract technologies such as biological enzyme and ultrasonic method are most popular. Biological enzyme functions at the plant's material surface destruct cell wall, reduces the resistance of extracting colorant from the cells, so as to improve the extract yield, with low-temperature high purity and less pollution character. Ultrasonic method is a broken method. Ultrasound stays in plant cells longer and deeper than an electromagnetic wave can penetrate, and the effective components of the plant can be extracted easily. In recent years, there are many reports on extracting natural dyes by both enzyme-ultrasonic methods.

Wen et al. investigated the impact of extraction yield by enzyme - ultrasonic method on (cortex phellodendri, rubia) planet. It has been shown that the productivity of natural plant dyes can be increased using biological and technical ultrasonic enzymes together, with high efficiency, energy saving and dimming features [45].

Tiwari et al. The use of ultrasound-mediated enzymes with the help of extraction procedures has been used to extract dye from (pomegranate skin). Optimal factors for color extraction were observed at $\mathrm{pH} \mathrm{10}$, extraction time $40 \mathrm{~min}$ and temperature $50{ }^{\circ} \mathrm{C}$. Ultrasound returns with enzyme-assisted assistance were observed in $29.2 \%, 26.5 \%, 35.6 \%$ and $8.8 \%$ in contrast. The acquired coloring has been used for cotton J. Text.Color. Polym. Sci.,16, No. 1 (2019) coloring, maintaining the ideal concentration of the $10 \%$ and $8 \%$ (corresponding weight) coloring pigeons [46].

Ultrasonic with other traditional methods of extraction:

Vázquez et al. reported that the ultrasonic extraction method yield a $168 \mathrm{mg} / \mathrm{g}$ dry weight extract in the anthraquinones of the Rubiáceae stalks, exceeding the Soxhlet yield $(34 \mathrm{Mg} / \mathrm{g})$. In addition, there was a reduction in recovery time by 16 to $2 \mathrm{~h}$; a reduction in the amount of solvent used (from $36 \mathrm{~mL} / \mathrm{g}$ to $20 \mathrm{~mL} / \mathrm{g}$ ) was observed [47].

Similarly, Cai et al., reported the main efficiency in the recovery of phenolic compounds from purple potatoes using the ultrasound method, with $22 \%$ increase in polyphenols compared to accelerated solvent extraction. This trend was also observed with flavonoid recovery, which showed an increase of $18.3 \mathrm{r}$ this value [48]. Péreza et al. noted that an increase in the production of phenolic compounds from olefin leaves by ultrasound $(47 \mathrm{mg})$ compared with conventional extraction $(27 \mathrm{mg})$, and chlorogenic acid as the major compound. Pan et al. reported that ultrasound method reduced the time of phenolic compounds extracted from pomegranate peels by $87 \%$ and provided an antioxidant activity greater than $22 \%$ greater than that obtained by soaking [49-50]. Kamel et al. investigation Cotton fabrics were dyed natural coloring materials extracted from Turmeric Curcuma Longa using conventional heating method and ultrasonic power method. About $47 \%$ of increase in the absorption of turmeric dye was informed using ultrasound dyeing, where the quantity of dye extracted by ultrasound technology was $41 \%$ higher than conventional extraction. Finally, it confirmed that ultrasonic extract method was much more excellent than traditional process. According to the researches above we can see, both enzyme and ultrasonic technology are able to increase the extract yield in the extracting process of natural plant dyestuff [51].

\section{References}

1. S. Rana, S. Pichandi, S. Parveen and R. Fangueiro, Roadmap to Sustainable Textiles and Clothing, Subramanian Senthilkannan Muthu, Hong Kong, Hong Kong SAR, pp. 1-35 (2014)

2. M. Ioelovich, Cellulose as a Nanostructured Polymer: A short review, bioresorces.com, 3, pp. 1403-1413 (2008), 
3. S. Kalia, A. Dufresne, B. M. Cherian, B. S. Kaith, L. Av'erous, J. Njuguna, and E. Nassiopoulos, Cellulose-Based Bio-and Nanocomposites: A Review, International Journal of Polymer Science, pp. 35 (2011).

4. D. Lavanya, P. K. Kulkarni, M. Dixit, P. K. Raavi, and L. N. Krishna, Sources of Cellulose and Their Applications-A Review, International Journal of Drug Formulation and Research, 2, pp. 19-38 (2011)

5. L. Y. Mwaikambo, Review of the History, Properties and Application of Plant Fibers, African Journal of Science and Technology, 7, pp. 120-133 (2006).

6. R. Singh and S. Srivastava, Exploration of Flower Based Natural Dyes - A Review, Research Journal of Recent Sciences, 4, pp. 6-8 (2015)

7. S. Saxena and A. Raja, Natural Dyes: Sources, Chemistry, Application and Sustainability Issues, Roadmap to Sustainable Textiles and Clothing: Eco-friendly Raw Materials, Technologies, and Processing Methods, S.S. Muthu, Singapore, Springer Singapore pp. 38-88 (2014).

8. M. Yusuf, M. Shabbir, and F. Mohammad, Natural Colorants: Historical, Processing and Sustainable Prospects, Journal of Natural Products and Bioprospecting, 7, pp. 123-145 (2017).

9. S. Verma and G. Gupta, Natural dyes and its Applications: A brief review, International Journal of Research and Analytical Reviews, 4, pp. 57-60 (2017).

10. M. L. Gulrajani , D. Gupta, and S. R. Maulik, Dyeing of Textiles with Natural Dyes, Indian Journal Fibre Textile Research, 24, pp. 288-294. (1999)

11. M. L. Gulrajani, S. Bhaumik, W. Oppermann and G. Hardtmann, Natural Dyes, Indian Journal Fibre Textile Research, 28, pp. 215-221 (2003).

12. B. Chengaiah, K. Mallikarjuna, K. M. Kumar, M. Alagusundaram \& C. M. Chetty, Medicinal Importance of Natural Dyes A Review, International Journal of PharmTech Research, 2, pp. 144-154. (2010)

13. P. Samanta, D. Singhee and A. M. Samanta, Fundamentals of Natural Dyeing of Textiles: Pros and Cons, Current Trends in Fashion Technology Textile Engineering, 2, pp. 001-008 (2018).

14. I. Alouani, M. O. Idrissi, M. Draoui, and M. Bouatia, Review: From Screening to Application of Moroccan Dyeing Plants: Chemical Groups and
Botanical Distribution, International Journal of Pharmacy and Pharmaceutical Sciences, 8, pp. 2131 (2016).

15. R. Singh and S. Srivastava, A Critical Review on Extraction of Natural Dyes From Leaves, International Journal of Home Science, 3, pp. 100103. (2017)

16. M. B. Kasiri and S. Safapour, Natural Dyes and Antimicrobials for Green Treatment of Textiles, Environmental Chemistry Letters, 12, pp. 1-13. (2014)

17. K. Sinha, P. D. Saha, V. Ramya and S. Datta, Improved Extraction of Natural Blue dye from Butterfly Pea using Microwave Assisted Methodology to Reduce the Effect of Synthetic Blue Dye, International Journal of Chemical Technology, 4, pp. 57-65 (2012)

18. S. Adeel, S. Ali, I. A. Bhatti and F. Zsila, Dyeing of Cotton Fabric using Pomegranate (Punica granatum) Aqueous Extract, Asian Journal of Chemistry, 21, pp. 3493-3499 (2009)

19. S. P. Khattak, S. Rafique, B. Ahmad, T. Hussain and Z. E. Mujeeb, Evaluation of Fastness and Tensile Properties of Cotton Fabric Dyed with Root Extracts of Acacia Catechu by Padsteam Procedure, Journal of Science and Technology, 2, pp. 59-69 (2013)

20. I. I. Shuvo, A Step-by-Step Chemical Recipe to Dye Commercial Cotton with Natural Indigo Dyes in an Open Bath for the Beginners and Artisans, Journal of Textile Science \& Engineering, 8, pp. 1-8 (2018).

21. A. Hebeish, M. M. Kamel, H. M. Helmy and N. S. El Hawary, Innovative Technology for Multifunctionalization of Cotton Fabric through Cellulase Biotreatment, Reactive Dyeing and Easy Care Finishing, Egyptian Journal of Chemistry, 56, pp. 367- 377 (2013).

22. M. M. El-Zawahry, Ecofriendly dyeing of linen fabric with natural dyes using different enzymes complexes, Man-Made Textiles in India, 52, pp. 337-343 (2009).

23. Y. Zhao, Y. Miao, and L. Zhao, Studies on extracted anthocyaninsn in indigo slag with cellulase and pectic enzymes by enzyme hydrolysis extraction method, Journal of Chinese Food, 8, pp. 75-79 (2008).

24. J. Cai, The application of enzyme in lycopene extracting process, Journal Hubei University of Tehnology, 20, pp. 8-10. (2005),

J. Text.Color. Polym. Sci.,16, No. 1 (2019) 
25. B. Qiu, W. Chen, and Q. Wang, Comparer of water extract and pectase adding in the extract process of gardenia yellow, Food Industry, 1, pp. 29-31 (2008).

26. Y. Z. Zhao, L. N. Du, C. T. Lu, Y. Guang, S. Ping, Potential and problems in ultrasound-responsive drug delivery systems, International Journal of Nanomedicine,8, pp. 1621- 1633 (2013).

27. N. S. Ahmed and R. M. El-Shishtawy, The use of new technologies in coloration of textile fibers, Journal of Materials Science, 45,1143-1153 (2010)

28. K. H. Prabhu and A. S. Bhute, Plant based natural dyes and mordnats: A Review, Journal of Natural Product and Plant Resource, 2, pp. 649-664 (2012).

29. M. M. Kamel, M. M. El Zawahry, N. S. E. Ahmed, and F. Abdelghaffar, Ultrasonic dyeing of cationized cotton fabric with natural dye. Part 2: cationization of cotton using Quat 188," Industrial Crops and Products, 34, pp. 1410-1417 (2011).

30. N. A. Abdul Rahman, S. M. Tumin and R. Tajuddin, Optimization of Ultrasonic Extraction Method of Natural Dyes from Xylocarpus Moluccensis, International Journal of Bioscience, Biochemistry and Bioinformatics, 3, pp. 53-55 (2013).

31. P. K. Mishra, P. Singh, K. K. Gupta, H. Tiwari and P. Srivastava, Extraction of natural dye from Dahlia variabilis using ultrasound, Indian Journal of Fibre \& Textile Research, 37, pp. 83-86 (2012).

32. I. D. Febriana, H. S. Kusuma, S. Gala and M. Mahfud, The Effect of Temperature on Extraction of Swietenia Mahagoni by Ultrasound-assisted Extraction (UAE) Method, ASEAN Journal of Chemical Engineering, 16, pp. 44-46 (2016).

33. C. Zhao, D. Wan, and P. Zhang, Studies on extracted lycopene from fresh tomato by auxiliary function of ultrasonic extraction, Journal Hubei Technology University, 29, pp. 80-83 (2008).

34. B. Wang, J. Wang, and L. Zhao, The optimization of response surface method on capsicum red dyestuff extracting by ultrasonic method, Chinese Agricultural Science Bulletin, 24, pp. 96-101 (2008).

35. S. Jiang and J. Wu, Study on the extracting process of orange peel stuff by ultrasonic technology, Journal of Fiber Bioengineering and Informatics, 36, pp. 3934- 3940 (2008).

36. R. Guglani, Recent developments in textile dyeing techniques,https://www.fibre2fashion.com/ industry-article/3419/recent-developments-in-

. J. Text.Color. Polym. Sci.,16, No. 1 (2019) textile-dyeing-techniques?page $=3$ (2008).

37. B. Y. Büyükakinci, Usage of Microwave Energy in Turkish Textile Production Sector, Energy Procedia, 14, pp. 424 - 431 (2012).

38. F, K. Yuen and B. H. Hameed, Recent developments in the preparation and regeneration of activated carbons by microwaves, Advances in Colloid and Interface Science, 149, pp. 19-27 (2009).

39. K. Haggag, A. Ragheb, S. H. Nassar, M. Hashem, H. El Sayed and I. Abd El - Thalouth, Microwave Irradiation and its Application in Textile Industries,

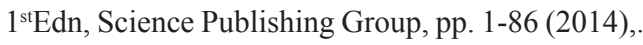

40. K. Sinha, P. D. Saha, V. Ramya and S. Datta, Improved Extraction of Natural Blue dye from Butterfly Pea using Microwave Assisted Methodology to Reduce the Effect of Synthetic Blue Dye, International Journal of Chemical Technology, 4, pp.57-65 (2012).

41. S. Gala, S. Sumarno, and M. Mahfud, Microwaveassisted Extraction of Natural Dyes from Coleus atropurpureus Leaves: The Effect of Solvent, MATEC Web of Conferences, 156, pp. 1-4 (2018).

42. R. M. Hassan, A. F. Zulrushdi, A. M. Yusoff, N. Kawasaki, and N. A. Hassan, Comparisons between Conventional and Microwave-Assisted Extraction of Natural Colorant from Mesocarp and Exocarp of Cocus Nucifera, Journal of Materials Science and Engineering, 5, pp. 152-158 (2015).

43. K. Hemanthraj, M. Sudhanva and S. Bisht, Optimization of Extraction Parameters for Natural Dye from Pterocarpus santalinus by using Response Surface Methodology, Journal of Engineering Research and Applications, 9, pp.100-108 (2014).

44. W.Y. Ahmad, N. M. Noor, M. R. Ahmad, and M.I. Ab Kadir, Microwave-Assisted Extraction as a Rapid Extraction to Produce Natural Dyes from Pycnoporus sanguineus Mushroom, Proceedings of the International Colloquium in Textile Engineering, Fashion, Apparel and Design , pp.9598 (ICTEFAD 2014).

45. W. J. Liu, Y. Z. Cui, L. Zhang and S. F. Ren, Study on Extracting Natural Plant Dyestuff by Enzymeultrasonic Method and its Dyeing Ability, Journal of Fiber Bioengineering and Informatics, 2, pp. 25-30. (2014)

46. H. C. Tiwari, P. Singh, P. K. Mishra and P. Srivastava, Evaluation of various techniques for extraction of natural colorants from pomegranate rind - Ultrasound and enzyme assisted extraction, 
Indian Journal of Fibre \& Textile Research, 35, pp. 272-276 (2010).

47. M. F. Vázqueza, L. R. Cominib, R. E. Martinia, S. C. Montoyab, S. Bottinic, and J. L. Cabrerab, Comparisons between conventional, ultrasoundassisted and microwave-assisted methods for extraction of anthraquinones from Heterophyllaea pustulata Hook f. (Rubiaceae), Ultrasonics Sonochemistry, 21, pp. 478-484 (2014).

48. Z. Cai, Z. Qua, Y. Lan, S. Zhao, X. Ma, Q. Wan, P. Jing and P. Lic, Conventional, ultrasound-assisted, and accelerated-solvent extractions of anthocyanins from purple sweet potatoes, Food Chemistry, 197, pp. 266-272 (2016)

49. R. Péreza, R. Q. Piné, A. F. Gutiérreza and A. S. Carretero, Optimization of extraction method to obtain a phenolic compounds-rich extract from
Moringa oleifera Lam leaves, Industrial Crops and Products, 66, pp. 246-254 (2015).

50. Z. Pan, W. Qu, H. Ma, Griffiths G. Atungulu and T. H. McHugh, Continuous and pulsed ultrasoundassisted extractions of antioxidants from pomegranate peel, Ultrasonics Sonochemistry, 19, pp. 365-372 (2012).

51. M. M. Kamel, , M. El-Hossamy, H. M. Helmy and N. S. El Hawary, Some studies on dyeing properties of cotton fabrics with Curcuma longa (Turmeric) (roots) using ultrasonic method (part I), Man-Made Textiles, 51, pp. 267-273 (2008).

(Received 11/2/2019; accepted $13 / 3 / 2019$ )

$$
\begin{aligned}
& \text { أصباغ طبيعية عالية الأداء للألياف السليلوزية ـ الجزء } \\
& \text { نانسي سياو سعد الهواري } \\
& \text { قسم الصباغة والطباعة و المساعدين ، شعبة بحوث الصناعات النسيجية ، المركز القومي للبحوث ، } \\
& \text { الجيزة- مصر منام }
\end{aligned}
$$

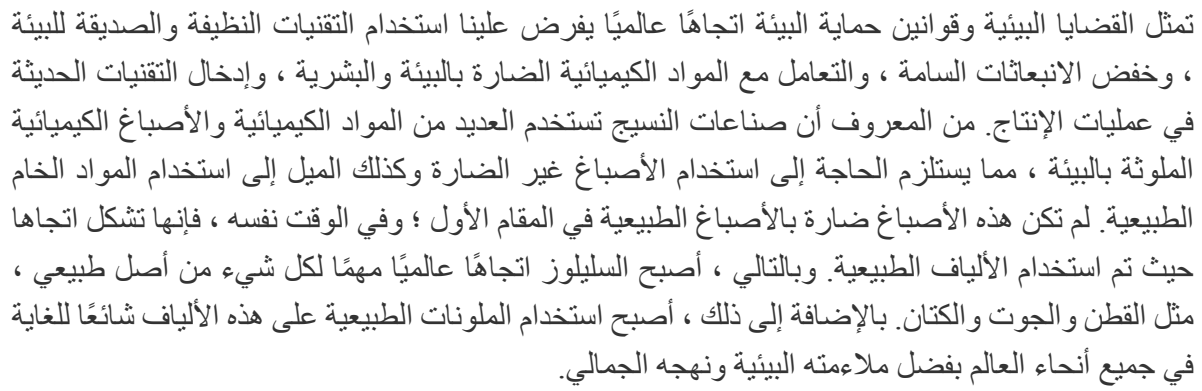

